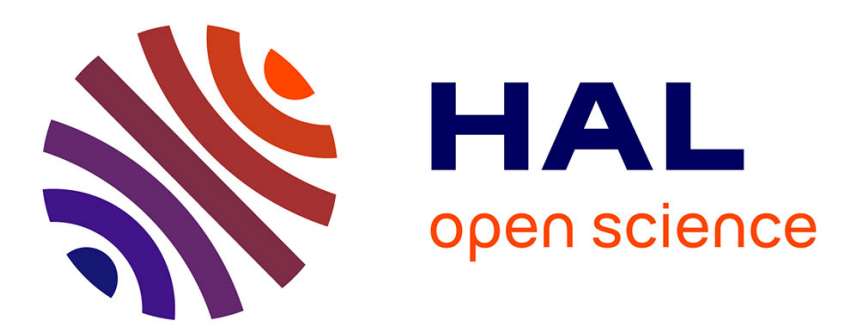

\title{
Damage analysis and fracture toughness evaluation in a thin woven composite laminate under static tension using infrared thermography
}

Teddy Lisle, Christophe Bouvet, Marie-Laetitia Pastor, Philippe Marguerès, Roberto Prieto Corral

\section{To cite this version:}

Teddy Lisle, Christophe Bouvet, Marie-Laetitia Pastor, Philippe Marguerès, Roberto Prieto Corral. Damage analysis and fracture toughness evaluation in a thin woven composite laminate under static tension using infrared thermography. Composites Part A: Applied Science and Manufacturing, 2013, vol. 53, pp. 75-87. 10.1016/j.compositesa.2013.06.004 . hal-00858882

\section{HAL Id: hal-00858882 \\ https://hal.science/hal-00858882}

Submitted on 6 Sep 2013

HAL is a multi-disciplinary open access archive for the deposit and dissemination of scientific research documents, whether they are published or not. The documents may come from teaching and research institutions in France or abroad, or from public or private research centers.
L'archive ouverte pluridisciplinaire HAL, est destinée au dépôt et à la diffusion de documents scientifiques de niveau recherche, publiés ou non, émanant des établissements d'enseignement et de recherche français ou étrangers, des laboratoires publics ou privés. 


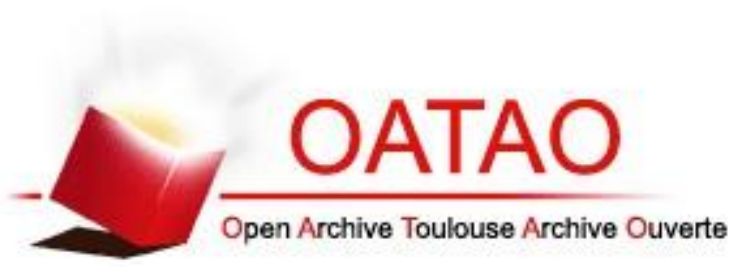

\section{Open Archive Toulouse Archive Ouverte (OATAO)}

OATAO is an open access repository that collects the work of Toulouse researchers and makes it freely available over the web where possible.

This is an author-deposited version published in: http://oatao.univ-toulouse.fr/ Eprints ID: 9324

To link to this article: DOI: 10.1016/j.compositesa.2013.06.004

URL: http://dx.doi.org/10.1016/j.compositesa.2013.06.004

To cite this version: Lisle, Teddy and Bouvet, Christophe and Pastor, Marie-Laetitia and Margueres, Philippe and Prieto Corral, Roberto Damage analysis and fracture toughness evaluation in a thin woven composite laminate under static tension using infrared thermography. (2013) Composites Part A: Applied Science and Manufacturing, vol. 53. pp. 75-87. ISSN 1359-835X

Any correspondence concerning this service should be sent to the repository administrator: staff-oatao@inp-toulouse.fr 


\title{
Damage analysis and fracture toughness evaluation in a thin woven composite laminate under static tension using infrared thermography
}

\author{
T. Lisle ${ }^{\mathrm{a}, *}$, C. Bouvet ${ }^{\mathrm{a}}$, M.L. Pastor ${ }^{\mathrm{a}}$, P. Margueres ${ }^{\mathrm{a}}$, R. Prieto Corral ${ }^{\mathrm{b}}$ \\ ${ }^{a}$ Université de Toulouse, INSA, UPS, Mines Albi, ISAE, ICA (Institut Clément Ader), 10, Avenue Edouard Belin, 31055 Toulouse cedex 4, France \\ ${ }^{\mathrm{b}}$ Universidad Politécnica de Madrid (UPM), Escuela de Ingeniería Técnica Aeronaútica (EUITA), Plaza Cardenal Cisneros No 3, C.P. 28040 Madrid, Spain
}

A R T I C L E I N F O

Keywords:

A. Yarn

B. Fracture toughness

B. Transverse cracking

Infrared thermography

\begin{abstract}
A B S T R A C T
This work deals with the issue of damage growth in thin woven composite laminates subjected to tensile loading. The conducted tensile tests were monitored on-line with an infrared camera, and tested specimens were analysed using Scanning Electron Microscopy (SEM). Combined with SEM micrographs, observation of heat source fields enabled us to assess the damage sequence. Transverse weft cracking was confirmed to be the main damage mode and fiber breakage was the final damage leading to failure. For cracks which induce little variation of specimen stiffness, the classic "Compliance method" could not be used to compute energy release rate. Hence, we present here a new procedure based on the estimation of heat source fields to calculate the energy release rate associated with transverse weft cracking. The results are then compared to those computed with a simple 3D inverse model of the heat diffusion problem and those presented in the literature.
\end{abstract}

\section{Introduction}

The application of woven fabric composites in engineering structures has been significantly increased due to attractive characteristics, such as their excellent drapability over complex geometries, or their high damage tolerance. Even for simple solicitations, to predict the reliability by numerical modeling of woven structures is still tricky and requires assessing both the damage growth and the dissipated energy involved. Consequently this study aims to provide further information on the damage process of thin woven laminates and especially on the fracture toughness of transverse yarn cracking.

Because of the complex inhomogeneous microstructure, the weave architecture, and disparate meso-constituent properties, the failure process of woven composites is complex and involves a multitude of fracture modes (matrix cracking, inter-yarn and intra-yarn cracking, inter-ply and intra-ply delamination). Over the past decades, several authors have investigated the damage scenario of different woven composite laminates under quasi-static tensile loading [1-4]. For woven carbon and glass fiber-reinforced composites, transverse yarn cracking is the first readily observable type of damage occurring during tensile loading. As the strain increases, damage develops on the meso-scale by intra-yarn cracking and delamination, and on the micro-scale by local disbonding at

\footnotetext{
* Corresponding author. Tel.: +33 5613395 63; fax: +33 561339352 .

E-mail address: teddy.lisle@isae.fr (T. Lisle).
}

the fiber matrix interface as reported by John et al. [2]. The final macro fracture is characterized by dense cracking, intersection of several small cracks and fiber rupture.

In the case of woven laminates most conventional non-destructive techniques, such as X-ray radiography or ultrasonic C-scan, remain too inaccurate to detect damage such as transverse yarn cracking. Classically, this kind of damage is identified using optical micrography. Other techniques, such as acoustic emission, have also been used for on-line damage detection as well as for tracking the damage progression in woven laminates [1,4]. These techniques enable to quantitatively estimate the damage initiation stress but cannot provide accurate information on the damage location.

From the past 20 years, infrared thermography has thus been widely used to study the dissipative phenomena during necking localization in metal materials [5-8] or in semi-crystalline polymers [9]. Using the framework of irreversible thermodynamics, Chrysochoos et al. [10] have presented a methodology to estimate the internal heat sources associated with the dissipative phenomenon from temperature measurement of the sample surface. Estimation of these heat sources makes it possible to locate the damage in time and space and to evaluate the dissipated thermal energy. Nevertheless, the use of infrared thermography to study dissipated thermal energy is quite recent in composite materials and is essentially applied to fatigue loading. For example, Naderi et al. [11] used infrared thermography to characterize damage stage evolution by calculating the heat dissipated during fatigue loading of thin woven laminates. 
In the case of cracks inducing small variations in specimen stiffness, classic "Compliance" methods are inappropriate to compute the energy release rate. Nevertheless, using crack tip contour integral analysis [12,13], Freund and Hutchinson [14] and Soumahoro [15] have shown that the energy release rate is linked to dissipative work. In addition, since the early work of Taylor and Quinney [16], it is well known that dissipative work is mainly converted into heat in metallic $[6,17]$ and polymeric materials [18-20]. Hence, in this study we propose linking the energy release rate to the experimental heat sources. In this way, the energy release rate can be computed even for experiments where the stiffness variation remains small.

The paper begins with Section 2 where the thermomechanical framework and the energy release rate equation are presented. Section 3 describes the characteristics of the experimental procedure, the woven laminate, and the image processing method. Afterwards, in Section 4 the damage process is evaluated combining infrared measurement and SEM micrographs. The second part of Section 4 describes the methodology leading to the energy release rate evaluation for transverse yarn cracking based on the estimation of heat sources.

\section{Theoretical framework}

\subsection{Thermo-mechanical background}

Classical concepts and the results of Thermodynamics of Irreversible Processes are used to model the experimental results $[21,22]$. We considered the material as orthotropic and assumed that tensile testing can be described as a quasi-static process under the small perturbations hypothesis. For woven composites, damage develops at the microscopic scale into plasticity [23] and fiber/matrix decohesion [4]. Then, as the strain increases, the combination of these damage modes leads to matrix cracking as reported by Okabe et al. [24]. The chosen state variables were thus the absolute temperature $T$, the linearized strain tensor $\boldsymbol{\varepsilon}$, a scalar vector $\alpha$ of $n$ internal variables governing strain hardening and $\boldsymbol{D}$ the damage tensor modeling decohesion plus any micro-fracture. Strain partitioning of the thermoelastic part and plastic part is adopted [22]: $\boldsymbol{\varepsilon}=\boldsymbol{\varepsilon}_{e}+\boldsymbol{\varepsilon}_{p}$. Introducing the specific Helmholtz free energy $\psi=\psi$ $\left(T, \boldsymbol{\varepsilon}-\boldsymbol{\varepsilon}_{p}, \boldsymbol{\alpha}\right)$ and combining the first and the second principle of thermodynamics, the local heat diffusion equation is written as:

$\rho C_{\varepsilon, \alpha} \dot{T}+\operatorname{div} \mathbf{q}=\Phi_{i n t}+\rho T \psi_{, T \varepsilon}: \dot{\boldsymbol{\varepsilon}}+\rho T \psi_{, T \alpha}: \dot{\alpha}+r_{e}$

where $C_{\varepsilon, \alpha}$ denotes the specific heat capacity at $\boldsymbol{\varepsilon}$ and $\boldsymbol{\alpha}$ constant, and $r_{e}$ the external volume heat supply. $\rho$ is the mass density and q the heat flux vector. The right-hand side of Eq. (1) groups all types of heat sources induced by the deformation process. The thermomechanical coupling terms $\rho T \psi_{, T \varepsilon}: \dot{\boldsymbol{\varepsilon}}$ and $\rho T \psi_{, T \alpha}: \dot{\boldsymbol{\alpha}}$ respectively represent the volume heat rate due to thermoelastic coupling and the volume heat rate resulting from coupling between the internal variable $(\boldsymbol{\alpha})$ and temperature $T$. The intrinsic dissipation $\Phi_{\text {int }}$ characterizes the volume rate of mechanical energy dissipated as heat and can be expressed as follows [22]:

$$
\begin{aligned}
\Phi_{i n t} & =\boldsymbol{\sigma}: \dot{\boldsymbol{\varepsilon}}_{p}+\boldsymbol{Y}: \dot{\boldsymbol{D}}-\boldsymbol{A}_{i} \cdot \dot{\boldsymbol{\alpha}}_{i} \geqslant 0 \quad \text { with } \boldsymbol{Y}=-\rho \frac{\partial \psi}{\partial \boldsymbol{D}} \text { and } \boldsymbol{A}_{i} \\
& =\rho \frac{\partial \psi}{\partial \boldsymbol{\alpha}_{i}}
\end{aligned}
$$

where $\boldsymbol{\sigma}$ is the Cauchy stress tensor. $\boldsymbol{Y}$ denotes the thermodynamic force associated with the damage tensor $\boldsymbol{D}$ classically called the damage energy release rate, and $\boldsymbol{A}_{i}$ represents the hardening variable. Finally, the determination of the left-hand side of Eq. (1) leads to a local evaluation of the total volume heat sources throughout the specimen.

\subsection{Two-dimensional heat diffusion problem}

The main problem is that thermal information given by the infrared camera only concerns surface temperature fields. Hence to deduce the distribution of heat sources evolved in the volume of the sample from thermal field measurements involves to solve the 3D inverse heat diffusion problem. However, the inverse problem remains ill-posed without additional information on heat source distribution through the thickness [25]. Nevertheless, under small thermal gradient conditions through the thickness, Eq. (1) can be simplified to directly link local heat sources with the surface temperature fields $[5,6,9]$. Indeed, in the case of a thin sample, a homogeneous depth-wise distribution of temperature and internal heat sources can be considered. Tested specimens were thus considered as thin orthotropic sheet samples. By noting $x, y$, and $z$, respectively the spatial coordinates in the width, length and thickness of the specimen, the following hypotheses were put forward in accordance with our experimental conditions:

- the specific heat $C_{\varepsilon, \alpha}$ and the mass density $\rho$ are material constants independent of the thermodynamic states $(\varepsilon, T, \boldsymbol{\alpha}) C_{\varepsilon}$ $\alpha=C$;

- the quantity of fiber being equal in the weft and warp directions, the longitudinal and transverse conductivities are supposed to be the same. The thermal conductivity tensor which is assumed to remain constant during testing is then expressed as follows [26]:

$$
\boldsymbol{k}=\left(\begin{array}{ccc}
k_{x x} & 0 & 0 \\
0 & k_{y y}=k_{x x} & 0 \\
0 & 0 & k_{z z}
\end{array}\right)
$$

- the external heat supply $r_{e}$ due to heat exchange by radiation is time independent $[5,10]$. This implies that the initial equilibrium thermal temperature field $T_{0}$ satisfies: $-\operatorname{div}\left(\boldsymbol{k} \operatorname{grad} T_{0}\right)=r_{e}$;

- considering low velocity displacement and small gradient temperature amplitudes, the convective terms resulting from the material time derivative are neglected [5];

- temperature variation induced by the occurrence of damage is assumed to be too small to modify the internal state of the material. In this context, couplings between temperature and internal variables are thus insignificant, $\rho T \psi_{, T \alpha}: \dot{\alpha} \approx 0$;

Under these assumptions, the local heat diffusion Eq. (1) can be rewritten as follows:

$\rho C \frac{\partial \theta}{\partial t}-\left[k_{x x} \frac{\partial^{2} \theta}{\partial x^{2}}+k_{x x} \frac{\partial^{2} \theta}{\partial y^{2}}+k_{z z} \frac{\partial^{2} \theta}{\partial z^{2}}\right]=\Phi_{\text {int }}+s_{\text {the }}=\omega_{\text {hs }}$

where $\theta=T-T_{0}$ represents the temperature variation between the current state and the initial equilibrium state $T_{0} . S_{\text {the }}$ is the thermoelastic coupling term $\rho T \psi_{, T \varepsilon}: \dot{\boldsymbol{\varepsilon}}$ while $\omega_{h s}$ denotes the total volume heat sources. Considering a homogeneous depth-wise distribution of the volume heat sources, the measured surface temperature field is assumed to be equal to the temperature averaged across the thickness noted as $\bar{\theta}(x, y, t)$. In this context, integration of Eq. (4) across the thickness under linear uniform Fourier conditions at the specimen boundary [5], leads to the following 2D diffusion problem:

$\rho C \frac{\partial \bar{\theta}}{\partial t}-k_{x x}\left[\frac{\partial^{2} \bar{\theta}}{\partial x^{2}}+\frac{\partial^{2} \bar{\theta}}{\partial y^{2}}\right]+\frac{\bar{\theta}}{\tau_{t h}}=\bar{\Phi}_{\text {int }}+\bar{s}_{\text {the }}=\bar{\omega}_{\text {hs }}$

where $\bar{\omega}_{h s}=\bar{\Phi}_{\text {int }}+\bar{s}_{\text {the }}$ are the overall depth-wise averaged volume heat sources. $\tau_{t h}$ represents a time constant characterizing the heat losses due to radiation and convection through the sample surfaces of normals $\pm \vec{z}$. This two-dimensional diffusion equation will 
constitute the starting point of the experimental work presented hereafter.

\subsection{Energy release rate estimation from dissipated heat}

During crack propagation, a fraction of the potential energy is made available to the fracture process. This specific strain energy release rate $G$ is mainly converted into plastic work, specific surface energy and kinetic energy [27]. The main part of the irreversible work is transformed into heat [16] while the rest of the energy is used to modify the molecular structure of the material. The authors observed that the proportion of irreversible work consumed as heat is conventionally between $70 \%$ and $100 \%[6,17]$ for metallic materials and between $50 \%$ and $90 \%$ for polymers [18-20]. Moreover, [28,29] observed that even in brittle material such as glass, the thermal energy was nearly as high as the energy released.

Using the same approach as Griffith [30], in this section we present an energy balance leading to a link between the energy release rate and the dissipated heat. We consider here a volume $\Omega$ containing a macro crack. After quasi-static (i.e. stable, $d W_{\text {cin }}=0$ ) crack growth of area $d S$, the variation of the external mechanical energy $d W_{\text {ext }}$ is assumed to decompose into reversible (elastic) and irreversible (anelastic) parts as follows:

$d W_{\text {ext }}=d W_{e}+d W_{\text {irreversible }}$

where $d W_{\text {ext }}$ is defined as the double integral of $w_{\text {ext }}$ over the current volume of the sample and over the time $d t$ corresponding to the crack propagation $d S$ :

$d W_{\text {ext }}=\int_{t} \int_{\Omega} w_{\text {ext }} d V d t$

$w_{\text {ext }}$ is the mechanical power of the external forces. The irreversible part $d W_{\text {irreversible }}$ can in turn be expressed as the sum of a dissipated $d W_{\text {diss }}$ and stored energy $d W_{\text {stored }}$ :

$d W_{\text {irreversible }}=d W_{\text {diss }}+d W_{\text {stored }}$

After a step of macro crack growth, the dissipated mechanical energy is supposed to be the sum of the energy dissipated as heat plus the energy spent on the creation of new surfaces $d W_{\text {surf }}$ (energy required to break atomic links). As mentioned by Griffith [30], this rupture energy ( $d W_{\text {surf }}$ ) is twice the specific surface free energy $\gamma_{\text {surf }}$ multiplied by the cracked surface: $d W_{\text {surf }}=2 \gamma_{\text {surf }} d S$. Using Eq. (2), $d W_{\text {diss }}$ and $d W_{\text {stored }}$ can be rewritten as follows:

$d W_{\text {diss }}=\int_{t} \int_{\Omega} \Phi_{\text {int }} d V d t+d W_{\text {surf }}$ and

$d W_{\text {stored }}=\int_{t} \int_{\Omega} \boldsymbol{A}_{i} \cdot \dot{\alpha}_{i} d V d t$

At this point, let us introduce the ratio of mechanical energy converted into heat defined by:

$\beta=\frac{\int_{t} \Phi_{i n t} d t}{\int_{t}\left[\boldsymbol{\sigma}: \dot{\boldsymbol{\varepsilon}}_{p}+\boldsymbol{Y}: \dot{\boldsymbol{D}}\right] d t}$

In this study we assumed that beta is uniformly distributed throughout the domain $\Omega$. Then, combining Eqs. 6, 8, 9 and 10 , the energy release rate $G$ can be calculated with the following equation:

$G=\frac{d\left(W_{\text {ext }}-W_{e}\right)}{d S}=2 \cdot \gamma_{\text {surf }}+\frac{1}{\beta \cdot d S} \int_{t} \int_{\Omega} \Phi_{\text {int }} d V d t$

In the following, we only deal with the case of transverse yarn cracking in glass/epoxy woven laminates. In this context, during the fracture process thermoelastic couplings are neglected compared to the intrinsic mechanical dissipation $s_{\text {the }} \ll \Phi_{\text {int }} \approx \omega_{h s}$.
Moreover, assuming that the specific free surface energy is a small part of the total energy released [15,28,29], Eq. (11) simplifies to:

$G=\frac{1}{\beta \cdot d S} \int_{t} \int_{\Omega} \omega_{h s} d V d t$

Hence using Eq. (12), an estimation of the energy release rate associated with transverse yarn cracking will be obtained from experimental heat source measurements.

\section{Experimental procedure}

\subsection{Material and manufacturing}

The material studied is a glass/epoxy (913-45\%-7781) woven composite. The laminates are made of 8-harness satin balanced woven fabric prepreg plies with a fiber volume fraction of $50 \%$. The yarn size is $0.5 \mathrm{~mm}$ wide and $0.1 \mathrm{~mm}$ thick. 8-harness satin weaves exhibit ply asymmetry with one side predominately warp and the other predominately weft, see Fig. 1. Mechanical [31] and thermal properties of the laminate are summarized in Table 1. All samples were made of two prepreg plies with aligned warp direction. They were all manufactured with the warp woven face of each ply oriented upward the thickness. The top face is therefore a warp side while the underside is a weft. In this paper, an orthotropic laminate with the warp yarns of woven plies lined up with the tensile direction will be noted as $\left[0^{\circ}\right]$. As shown in Fig. $2 \mathrm{~b}$, the specimens were $30 \mathrm{~mm}$ wide and $0.65 \mathrm{~mm}$ thick with an approximate length between the tabs of $150 \mathrm{~mm}$.

\subsection{Test set-up}

Tension tests were performed on an electromechanical tension machine (INSTRON, capacity: $10 \mathrm{kN}$ ) at room temperature $(\approx 293 \mathrm{~K})$. The crosshead speed was set to $20 \mathrm{~mm} \mathrm{~min}^{-1}$ in order to limit the overall size of the thermal data while keeping a suitable frequency to capture quick thermal variation. Comparison with tests performed at lower speeds was made to ensure that no dynamic effects appear. The tensile direction was lined up with the warp direction of woven plies. An infrared camera (FLIR SC7000 MW) was used to monitor the thermal response of the sample surface during experiments. The infrared camera has a maximum resolution of $L_{0} \times l_{0}=320 \times 256$ pixels and a thermal resolution of $0.025 \mathrm{~K}$ for relative temperature measurement. Only a reduced fixed zone of $L_{x} \times l_{y}=325 \times 215$ pixels was chosen for the computation of the heat source field, see Fig. $2 \mathrm{~b}$. The spatial resolution (pixel size) determined by the focal distance is set at $0.16 \mathrm{~mm}$ (maximum magnification of the lens) in order to have at least 3 pixels per yarn. Thermal images were recorded at a frequency of $50 \mathrm{~Hz}$. In order to avoid thermal perturbations arising from the external environment, the specimens were enclosed in a rectangular box made of expansive foam. This box was painted black inside and covered with a black opaque fabric outside, as illustrated in Fig. 2a.

The face of the sample monitored by infrared camera was covered with a thin layer of black mat paint to maximize the surface emissivity. As previously mentioned, microfracturing of transverse yarns is the main observable damage in satin woven composites $[1,3,4]$. Hence, in this study, in order to accurately capture the temperature changes induced by transverse yarn micro-cracking, the sample face observed with the infrared camera was the weft face. To estimate the strain, an extensometer was glued to the sample warp face, as depicted in Fig. $2 \mathrm{~b}$. 


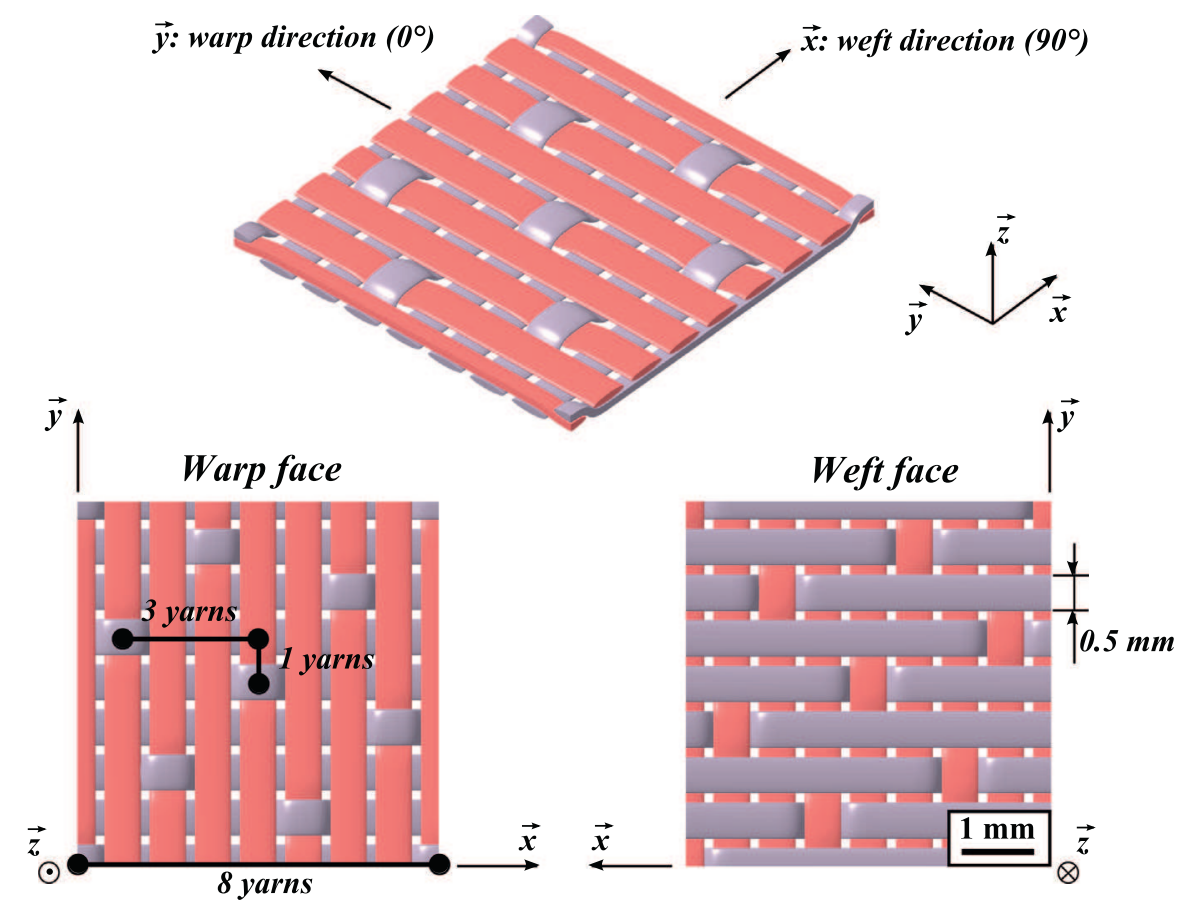

Fig. 1. Unit cell of the 8-harness satin glass/epoxy prepreg ply. (For interpretation of the references to color in this figure legend, the reader is referred to the web version of this article.)

Table 1

Mechanical and thermal properties of a glass/epoxy woven laminate.

\begin{tabular}{ll}
\hline Young's modulus in warp direction, $E_{y}(\mathrm{GPa})$ & 21.5 \\
Young's modulus in weft direction, $E_{x}(\mathrm{GPa})$ & 20.5 \\
Shear modulus, $G_{x y}(\mathrm{GPa})$ & 3.5 \\
Poisson ratio, $v_{x y}$ & 0.15 \\
Thermal conductivity in weft and warp direction, $k_{x x}, k_{y y}\left(\mathrm{~W} \mathrm{~m}^{-1} \mathrm{~K}^{-1}\right)-$ & 0.55 \\
$\quad[37]$ & \\
Thermal conductivity in the transverse direction, $k_{z z},\left(\mathrm{~W} \mathrm{~m}^{-1} \mathrm{~K}^{-1}\right)-$ & 0.35 \\
$\quad[37]$ & 882 \\
Specific heat, $C\left(\mathrm{~J} \mathrm{~kg}^{-1} \mathrm{~K}^{-1}\right)-[38]$ & 1730 \\
Density, $\rho\left(\mathrm{kg} \mathrm{m}^{-3}\right)$ &
\end{tabular}

\subsection{Infrared image processing}

The 2D local heat diffusion equation defined earlier (Eq. (5)) is the starting point of the methodology. As previously described, this equation directly links heat sources $\bar{\omega}_{h s}$ with the surface temperature variation of the sample $\bar{\theta}$. At any time $t$, for any pixel position $(x, y)$, the temperature variation field $\bar{\theta}(x, y, t)$ was then computed by subtracting the mean of the first ten measured thermal images $\bar{T}_{0}(x, y)$ (corresponding to the initial thermal equilibrium) from the current thermal image $\bar{T}(x, y, t)$. Using the left-hand side of Eq. (5), the volume heat sources $\bar{\omega}_{h s}(x, y, t)$ were estimated for each pixel $(x, y)$ position at any time $t$. However, the estimation of heat sources requires the evaluation of spatial and temporal differential operators from noisy thermal images. Thus before any differentiation, the thermal noise has to be reduced.

In this work noisy thermal images were locally fitted on square frames of $N_{x} \times N_{y}$ pixels using a parabolic surface function (2D second order polynomial) and a local least-squares fitting. The temporal derivative term was then estimated by centered finite differentiation, whereas spatial derivative terms were theoretically calculated from the parabolic surface function derivatives. As the yarn scale represents a key scale for damage in woven materials, the size of the approximation zone has to be close to the yarn scale $(\approx 3$ pixels $)$ to avoid excessive smoothing of the damage phenomenon in the yarn. Furthermore, the size of the approximation zone $\left(N_{x} \times N_{y}\right.$ pixels) has to be large enough to filter the noise, but small enough to detect small heterogeneous heat sources. Numerical tests were conducted to get a good compromise between these two criteria, as a reasonable calculation time. Finally, an approximation zone of $N_{x} \times N_{y}=5 \times 5$ square pixels was chosen to filter thermal data.

\section{Results and discussion}

\subsection{Damage initiation and growth in an 8-harness weave composite}

\subsubsection{Characterisation of damage using SEM}

Tensile tests were performed and stopped at different strain levels to perform SEM micrograph analysis. A selected piece of the tested laminate sample was observed as illustrated in Fig. 3b. The stress-strain curves and corresponding micrographs are respectively shown in Fig. 3a and Fig. 4. Transverse fracture of the weft yarns was the first damage observed, as indicated in the literature [1-4]. Initiation of the weft yarn fracture was considered by Osada et al. [3] to be caused by the bending deformation of the weft fiber bundle. Indeed as also observed by John et al. [2] under pure tension the crimped yarn tends to maintain a straight position and thus introduces stresses in the weft yarn. This leads to the transverse micro-fracture of the yarn. Nevertheless, we observed that first transverse cracks do not necessarily appear at the crimped region. This could mean that the crack formation is a result of a complicated crack formation mode, depending on the local stresses at the micro-scale.

Fig. 4 shows that weft yarn cracking occurred around the wellknown "knee point" identified around $\varepsilon_{y} \approx 0.7 \%$. This value is in accordance with the results of Osada et al. [3] obtained on thin satin woven laminates. From the knee point, with the increasing strain both the length and number of cracks extended in the weft yarns. Besides, as shown in the magnification of micrography (C), $\left(B^{\prime}\right)$ and $\left(C^{\prime}\right)$, cracks extended in the weft direction at the fiber/matrix interface. Picture (A') also shows that cracks followed the fiber/ 


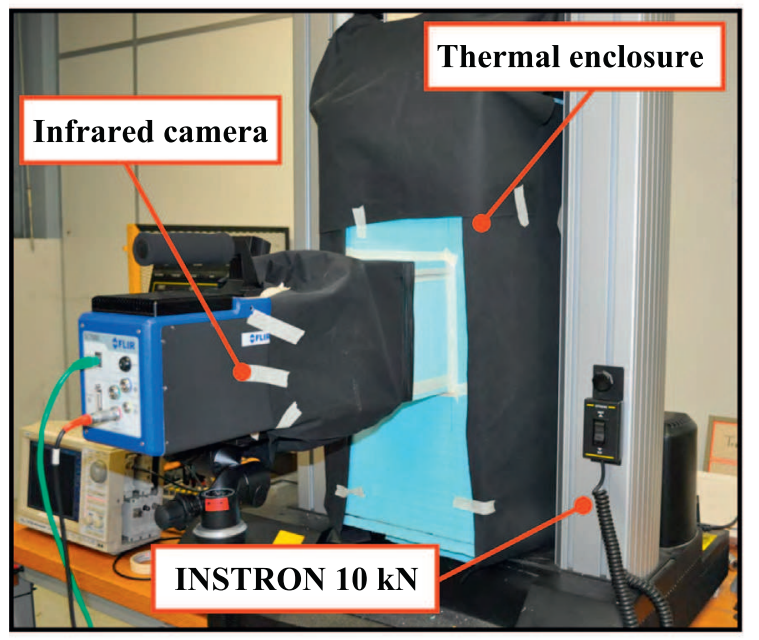

(a)

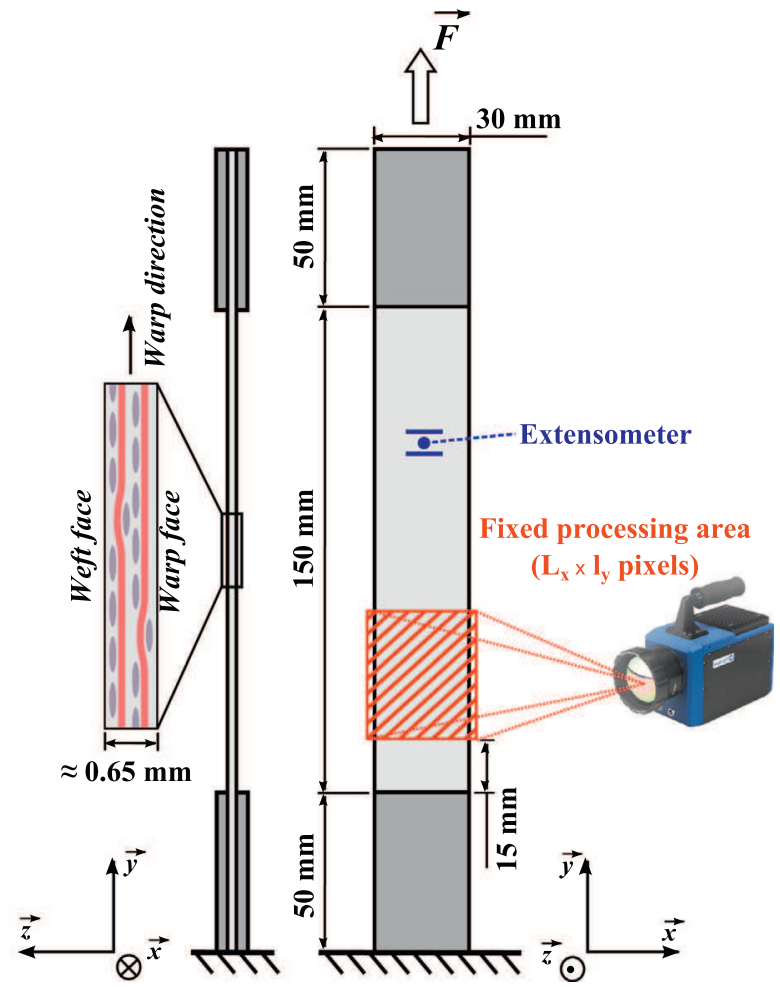

(b)

Fig. 2. (a) Experimental setup; (b) Specimen geometry, location of the fixed processing area and position of the extensometer. (For interpretation of the references to color in this figure legend, the reader is referred to the web version of this article.)

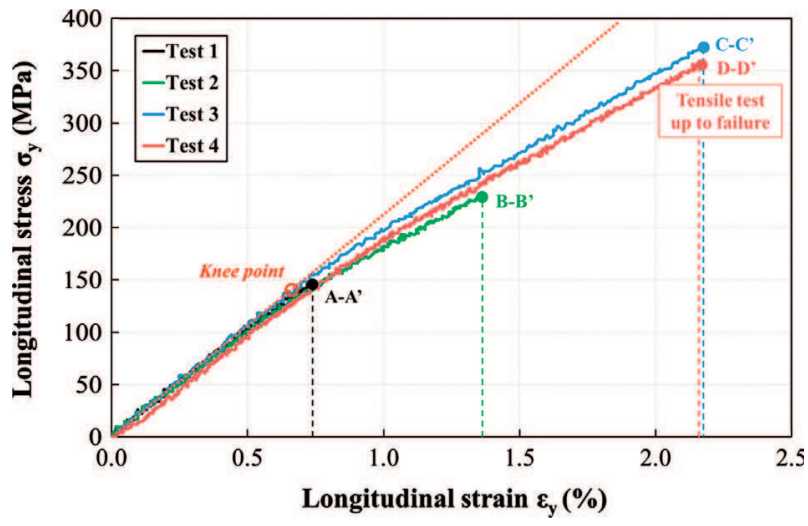

(a)

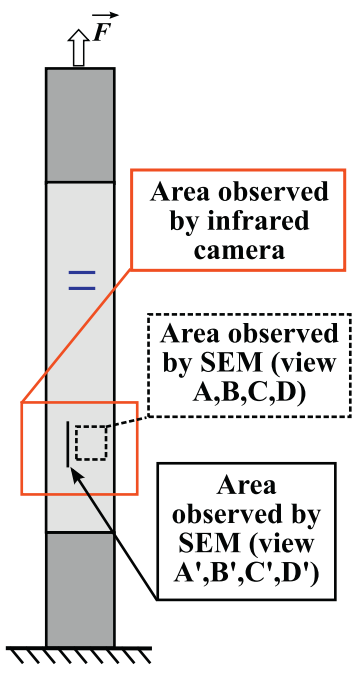

(b)

Fig. 3. (a) Stress-strain curves of tensile tests; (b) Location of the areas observed by SEM. (For interpretation of the references to color in this figure legend, the reader is referred to the web version of this article.

matrix interface in the thickness direction, as observed by Gao et al. [1]. In addition, magnification of micrography (C') illustrates the existence of local debonding at the fiber/matrix interface around transverse cracks. As observed by Hobbiebrunken et al. [32] and Okabe et al. [24], interfacial debonds are preferential zones for macroscopic crack propagation. Indeed, the previous authors observed that during loading, several interfacial cracks grow and connect to a macroscopic crack when the load increases. The post-mortem micrograph $\mathrm{D}$ shows that after failure, transverse micro-fractures extend toward the cross-over points of the woven plies. Multiple fractures were also detected along the warp yarn fibers on micrograph D', which might be due to shock wave propagation induced by the earliest fiber ruptures. Finally, as observed by Osada et al. [3], Daggumati et al. [4], we also observed that 




B

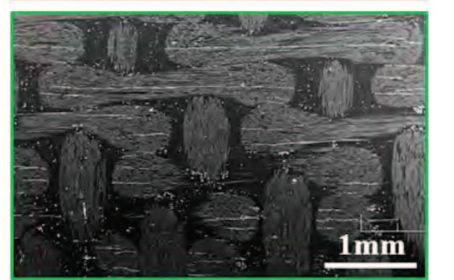

C



D
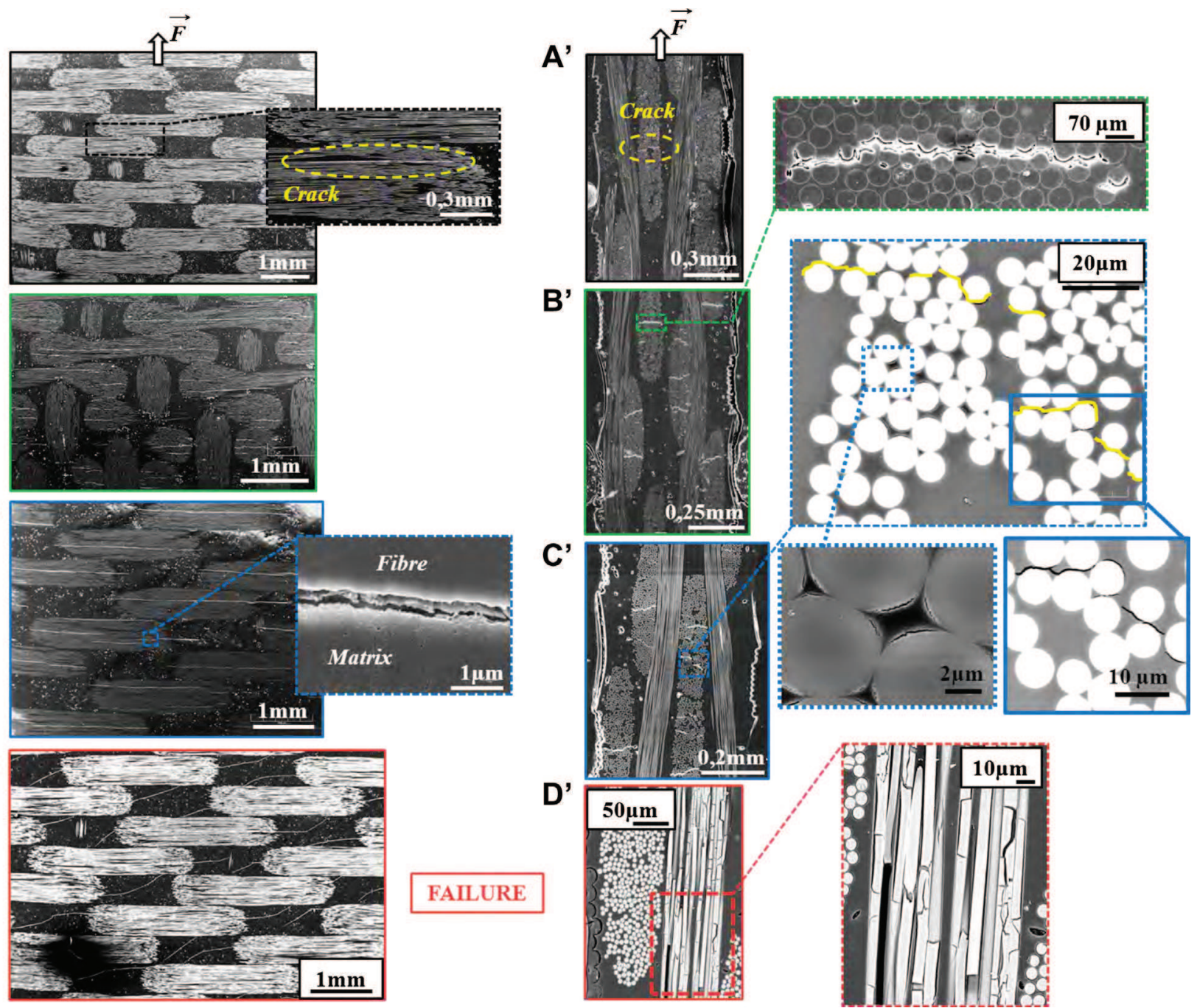

FAILURE

Fig. 4. SEM micrographs at different strain states, see Fig. 3a. (For interpretation of the references to color in this figure legend, the reader is referred to the web version of this article.)

the final failure of the specimen was caused by the combination of transverse crack densification, the intersection of several small cracks and warp fiber ruptures.

\subsubsection{Damage analysis from temperature field measurement}

In order to obtain additional information on the damage scenario, especially on the damage location, the temperature of the sample weft face was monitored with an infrared camera (Fig. 2). Fig. 5b shows the temperature variation field of the entire observed zone at a strain level of $1.25 \%$. The whole surface undergoes quasi homogeneous cooling due to the thermoelastic effect induced by the tensile deformation. Several small increases of temperature are also clearly identifiable. Magnification of one of these thermal patterns and the corresponding heat source field evolution are presented in Fig. $5 \mathrm{c}$ and d. As the weft face, the warp face of the laminate undergoes homogeneous cooling due to the thermoelastic effect. Because of the low thermal conductivity of the material through the thickness, the small increases of temperature observed on the weft face were barely visible on the warp face. This result confirms that the yarn cracking occurs mainly in the weft yarns, and thus that the warp face cannot be used to estimate the energy release rate associated with transverse yarn cracking.

Comparison between Fig. 5c, d and micrography Fig. 5e show that propagation of transverse yarn cracks induces temperature in- creases in the weft yarns. As seen in Fig. 5d, during crack propagation into the weft yarn, a localized dissipative heat source expands sharply in the weft tow (two images $\approx 0.04 \mathrm{~s}$ ). The heat source appears one image $(0.02 \mathrm{~s})$ before the image of the temperature increase due to the use of a centered finite difference scheme for the time derivative term estimation (see Eq. (5)). The dissipative heat sources represented in Fig. 5d illustrate that around the crack irreversible work develops over a band slightly greater than the yarn width $(\approx 0.8 \mathrm{~mm})$.

Thereafter, a spatial cartography of all the transverse microcracks can be obtained at any strain level by temporally accumulating experimental heat sources calculated on each image pixel. Fig. 6a presents the total cumulative volume energy $E_{\text {tot }}\left(\mathrm{J} \mathrm{m}^{-3}\right)$ cartography at three different levels of strain. The total amount of dissipated energy by thickness unit throughout the observed zone $W_{\text {tot }}\left(\mathrm{J} \mathrm{m}^{-1}\right)$ was plotted as a function of longitudinal strain in Fig. $6 \mathrm{~b}$. $W_{\text {tot }}$ and $E_{\text {tot }}$ were estimated using the following equations:

$$
\begin{aligned}
& E_{\text {tot }}(x, y, t)=\int_{0}^{t_{\text {tot }}} \omega_{h s}(x, y, t) d t \text { and } \\
& W_{\text {tot }}(t)=\int_{0}^{t_{\text {tot }}} \int_{0}^{L_{x}} \int_{0}^{l_{y}} \omega_{h s}(x, y, t) d x d y d t
\end{aligned}
$$


(a)



(b)



(c)
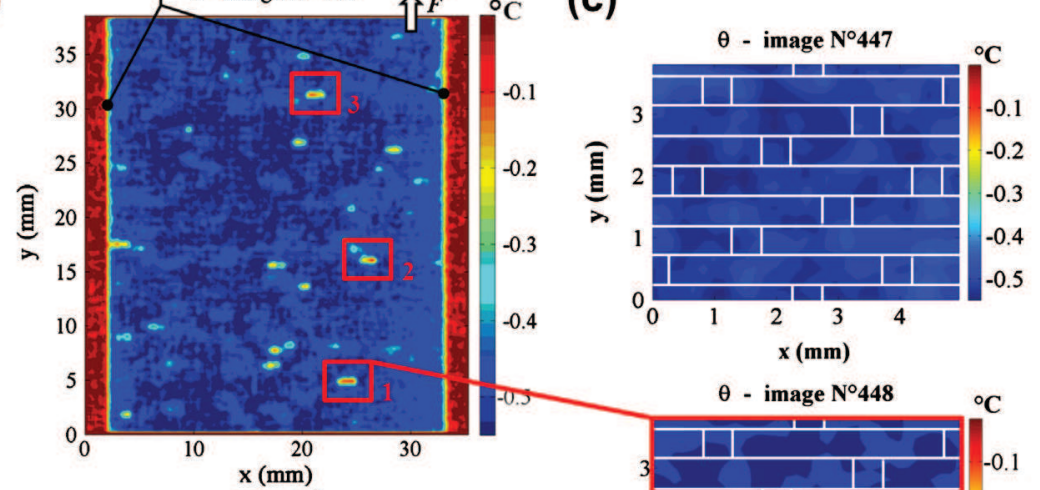

(d)

(e)
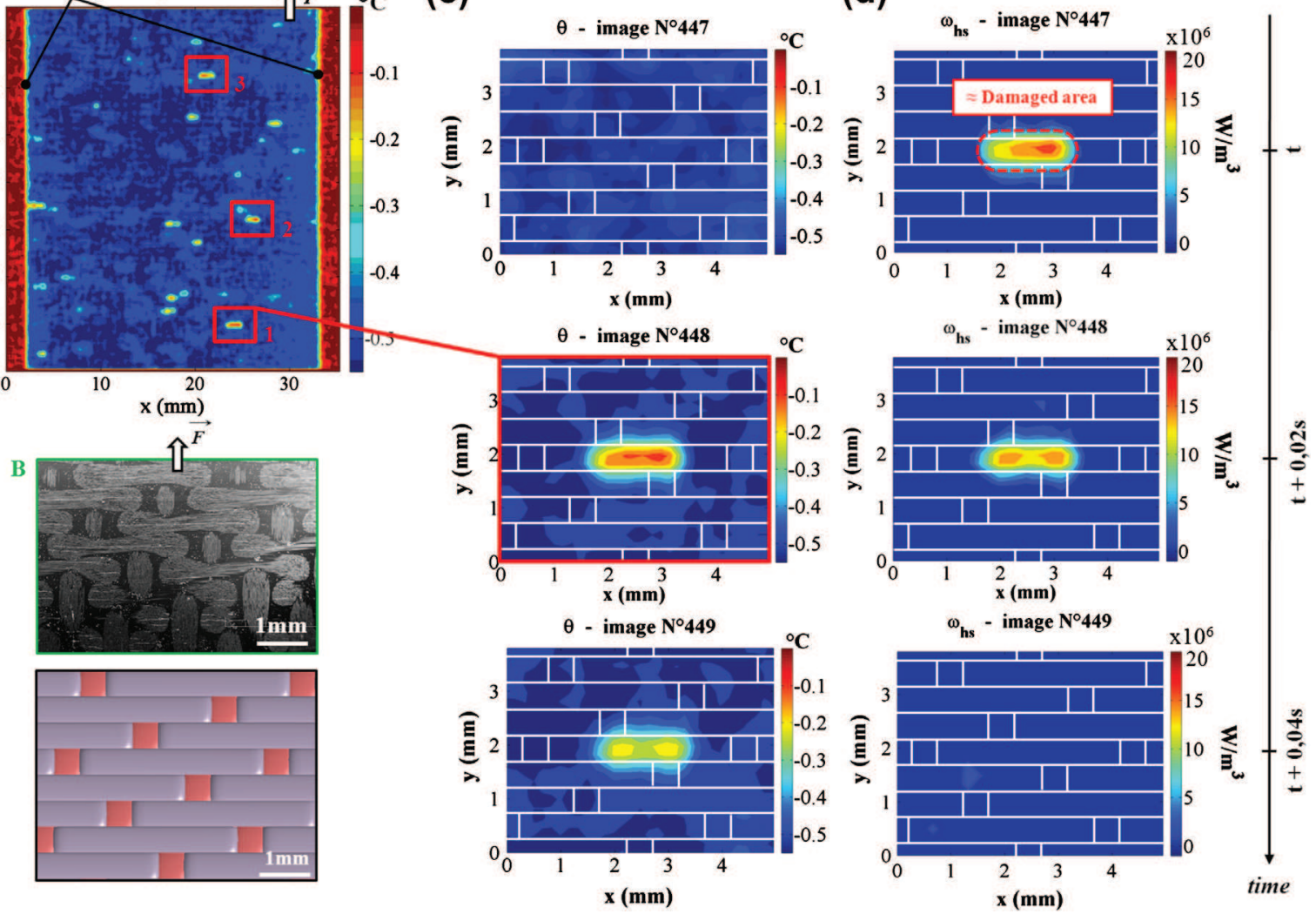

Fig. 5. (a) Stress-strain curve indicating selected pictures. (b) Temperature variation fields of the entire observed zone. (c) Temperature variation fields and (d) corresponding heat source fields with the weave pattern of the layered weft face. (e) SEM micrograph C and schematic representation of the weft face. (For interpretation of the references to color in this figure legend, the reader is referred to the web version of this article.)

where $t_{\text {tot }}$ represents the total integration time, $L x$ and $l_{y}$ denoting respectively the width and the length of the processing zone, see Fig. 2b. As expected, transverse yarns cracking occurs firstly around the knee point, see picture 330 in Fig. 6a. As we can observe, transverse cracks develop close to the left edge of the specimen, which might be due to a small misalignment of the sample between the grips. According to SEM micrographs previously presented, image $\mathrm{N}^{\circ} 448$ shows that transverse yarn cracks accumulate in several weft yarns as strain increases. Moreover, Fig. 6 illustrates that transverse matrix crack densification occurs essentially between $\varepsilon_{y} \approx 1 \%$ and $\varepsilon_{y} \approx 1.55 \%$. Afterwards, magnifications of pictures $\mathrm{N}^{\circ} 448$ to $\mathrm{N}^{\circ} 810$ in Fig. 6a show crack extensions as crack intersections between adjacent yarns. Fig. $6 \mathrm{~b}$ presents the total amount of energy dissi- pated by thickness unit $W_{\text {tot }}$. Until $1.55 \%$ of longitudinal strain, Fig. $6 \mathrm{~b}$ shows a strong increase in dissipated energy $W_{\text {tot }}$ due to rapid accumulation of transverse cracks. Then, as the strain increases, a change in the damage mode was observed. Indeed after $1.55 \%$ of longitudinal strain, we observed a decrease of the curve slope due to a slower accumulation of dissipative work. This phenomenon is attributed to the change of damage mode. Indeed, after $1.55 \%$ of longitudinal strain, we detected crack extension rather than accumulation of new transverse cracks as seen in Fig. 6a, although a few new cracks were observed. The magnification of picture $\mathrm{N}^{\circ} 810$ shows that close to the final failure point, cracks between adjacent yarns intersect. This result could explain the bifurcation of cracks toward the cross-over points of adjacent yarns observed 

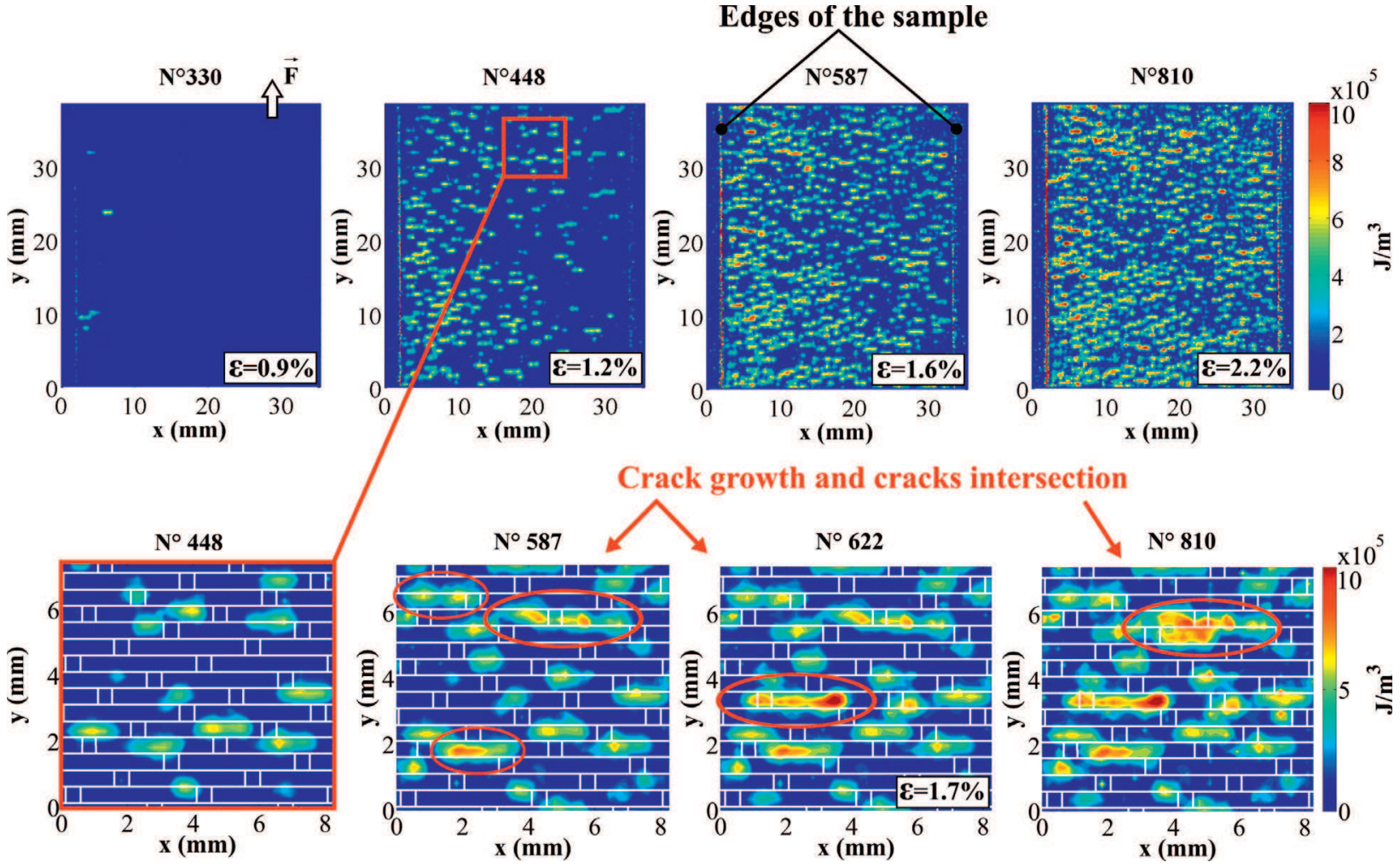

(a)

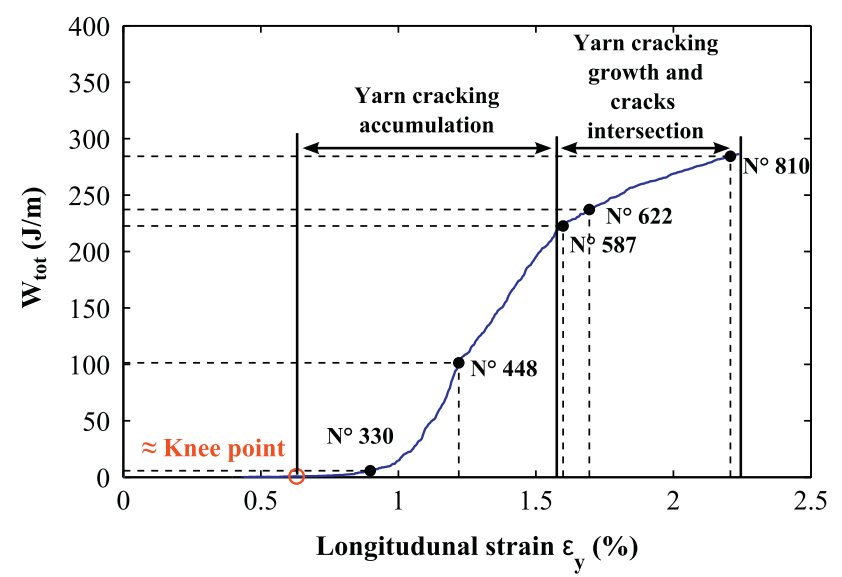

(b)

Fig. 6. (a) Temporally accumulated energy $E_{\text {tot }}$; (b) Evolution of the total amount of dissipated energy $W_{\text {tot }}$ as a function of longitudinal strain. (For interpretation of the references to color in this figure legend, the reader is referred to the web version of this article.)

on the post-mortem micrograph (D). Finally, as reported in the literature [1-4], image $\mathrm{N}^{\circ} 810$ demonstrates that close to the final failure point, most of the weft yarns exhibit micro-cracks.

\subsection{Energy release rate $(G)$ by transverse yarn cracking}

\subsubsection{G estimation from the $2 D$ heat diffusion equation}

As previously mentioned, Eq. (12) is used to estimate the energy release rate associated with transverse yarn cracking. Using the experimental heat source power $\bar{\omega}_{h s}$, Eq. (12) is rewritten as follows:

$G=\frac{1}{\beta} \cdot \frac{1}{e_{c} \cdot l_{c}} \int_{t} \int_{\Omega} \bar{\omega}_{h s} d V d t$ where $e_{c}$ and $l_{c}$ respectively denote the depth and the length of the cracked surface, as shown in Fig. 7. In order to capture the all the dissipated thermal energy associated with the yarn cracking, the area used to compute the energy release rate was chosen slightly higher than the heat source size, see Fig. 7a. The computation of the energy release rate also requires knowing the ratio of mechanical energy converted into heat noted as $\beta$. However, for the material used in this study no values are available in the literature. In addition, the value of this ratio is both strain and strain-rate sensitive $[18,19,29]$. With regard to values of $\beta$ in the literature for polymer materials, two cases were studied. In the first case, half of the mechanical energy is dissipated as heat: $\beta=0.5$ and in the second the thermal dissipated energy represents $90 \%$ of the total work: 
$\beta=0.9$. The true value of $G$ for intra yarn cracking should a priori be included in this range. The energy release rates calculated with the experimental procedure previously described are shown in Fig. 8. These experimental values represent the mean of twelve energy release rates estimated on two different specimens. The dispersion characterizes the minimum and maximum values of calculated $G$. As illustrated in Fig. 8, the energy release rates estimated in both cases ( $\beta=0.5$ and $\beta=0.9$ ) are in the same range as those reported in the literature for inter-laminar fracture toughness of glass/epoxy woven laminates. Due to disparate material properties and different cracking paths and modes for each woven fabric, these results are difficult to compare. However even if inter-laminar and intra-laminar fracture do not necessarily need to agree, they are both characterized by matrix cracking and crack propagation at the fiber/matrix interface. So it is not very surprising that the order of magnitude of the energy release rate matches quite well.

Finally, the micro-fracture of one weft yarn represents the cracking of approximately one quarter of the sample thickness. Thus to associate homogeneous heat sources through the thickness of the sample with transverse cracking may be unsuitable and may lead to underestimating the dissipated heat. In addition, to assume that cracks propagate as a straight line may lead to overestimating the energy release rate. Indeed Figs. 4 and $7 \mathrm{~b}$ clearly show that cracks in the thickness direction follow fiber/matrix interfaces. As observed in these figures, the crack length should be greater than the estimated length, and consequently $G$ should be lower. In order to figure out the validity of these previous hypotheses, a three dimensional heat diffusion problem was studied. The numerical model is presented in the following section.

\subsubsection{Comparison with a three-dimensional thermal analysis}

For woven laminates which exhibit low thermal diffusivity through the thickness, strong thermal gradients may occur and thus quantitative estimation of heat sources via the 2D heat diffusion equation (Eq. (5)) may introduce significant errors. As mentioned above, only one quarter of the sample thickness is cracked during yarn crack propagation. Due to the low thermal conductivity of the laminate through the thickness, no temperature increases were observed on the warp face during experiments. Hence, the quantitative estimation of the associated energy release rate requires solving the 3D thermal problem. However, as previously stated, to solve the 3D heat diffusion inverse problem without any information on the heat source volume distribution is an ill-

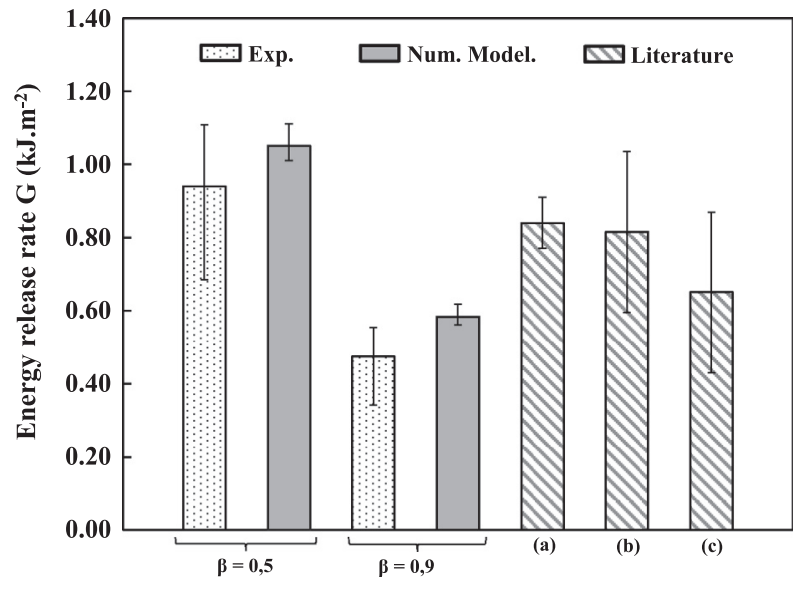

Fig. 8. Comparison of the energy release rate $G$ calculated from experimental $2 D$ heat source and from numerical modelling with the inter-laminar fracture toughness of several woven laminates; (a): 8 Harness (HS) woven Glass/epoxy, [34]; (b): 4 HS woven Glass/epoxy, [35]; (c): 5 HS woven Glass/epoxy, [36].

posed problem [25]. In this study, information from SEM observations and results from heat source fields calculated with Eq. (5), enabled us to assert the following hypotheses on the heat source distribution:

- when a crack propagates into a transverse yarn, the whole yarn thickness is cracked. The heat source depth accompanying weft yarn cracking is thus assumed to be equal to the yarn thickness $(\approx 0.1 \mathrm{~mm})$;

- the heat source is assumed to be uniformly distributed across the yarn thickness;

- the observation of heat source fields presented in Fig. 5e and Fig. 7a enables us to postulate that the spatial distribution of the heat source can be represented as a Gaussian function.

Considering these hypotheses, a representative function for heat source fields induced by transverse yarn cracking is proposed:

$$
\begin{aligned}
\omega_{h s}(x, y, z, t)= & \omega_{\max } \cdot e^{-\left(\frac{\left(x-x_{0}\right)^{2}}{2 \cdot \sigma_{x}^{2}}+\frac{\left(y-y_{0}\right)^{2}}{2 \cdot \sigma_{y}^{2}}\right)} \cdot e^{-\frac{\left(t-t_{0}\right)^{2}}{2 \cdot \sigma_{t}^{2}}} \cdot\left[H\left(z-z_{0}\right)\right. \\
& \left.-H\left(z-z_{1}\right)\right]
\end{aligned}
$$



(a)

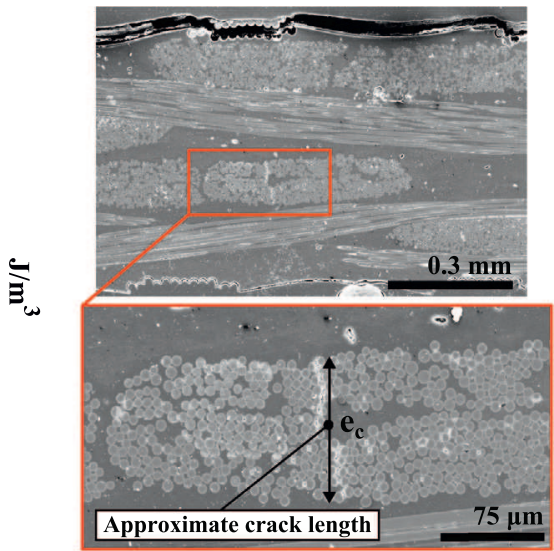

(b)

Fig. 7. (a) Approximate area used to compute the surface integral of the 2D heat sources and estimation of the total crack length; (b) Estimation of the cracked thickness. (For interpretation of the references to color in this figure legend, the reader is referred to the web version of this article.) 
where $\omega_{\max }$ denotes the heat source's peak. $x_{0}, y_{0}$ are respectively the longitudinal and transversal positions of the peak center, while $t_{0}$ represents the temporal position of the peak. $\sigma_{x}, \sigma_{y}$ and $\sigma_{t}$, classically called standard deviations, which in turn control the length, width and temporal distribution of the heat source. $H\left(z-z_{0}\right)$ $-H\left(z-z_{1}\right)$ is a rectangular function constructed with two Heaviside functions noted $H . z_{0}$ and $z_{1}$ are chosen in order to fit the thickness of the yarn, see Fig. 9. The infrared camera resolution is $0.16 \mathrm{~mm} /$ pixel. Thus to be close enough to experimental conditions, the in-plane spatial discretization parameters $\Delta x$ and $\Delta y$ are chosen equal to the camera resolution: $\Delta x=\Delta y=0.16 \mathrm{~mm}$. A thinner discretization was used in the thickness direction to accurately capture the thermal gradient through the thickness: $\Delta z=0.05 \mathrm{~mm}$. The resolution of the 3D heat diffusion equation (Eq. (1)) was implemented in MATLAB 2011b, using explicit programming and finite differentiation [33]. The temporal resolution was set small enough to ensure convergence: $\Delta t=0.001 \mathrm{~s}$ and the material properties used are summarized in Table 1.

The theoretical heat sources were calculated for three different transverse cracks over three distinct areas, as shown in Fig. 5b. To minimize the difference between experimental and theoretical temperature fields of the weft face, optimum values of the parameters $\omega_{\max }, \sigma_{x}, \sigma_{y}$ and $\sigma_{t}$ were estimated by dichotomy with the numerical model described earlier. The spatio-temporal localization parameters $x_{0}, y_{0}$, and $t_{0}$ were set to match those of the experimental heat sources. The sets of calculated parameters are presented in Table 2. For each computed heat source, the numerical temperature field of the weft face was compared with the experimental results. Typical results obtained after optimization of the heat source parameters are shown in Fig. 10 (zone noted 1 in Fig. 5b). Fig. 10c shows the temporal evolutions of the mean weft face temperature averaged over the rectangular surface drown in Fig. 10b. Whereas Fig. 10d and e present respectively the spatial temperature variation along the $X-X$ and $Y-Y$ lines at the temperature peak. As it can be seen in Fig. 10, identical results were obtained between experimental and numerical temperature fields of the weft face. Particularly, Fig. 10c shows a good correlation between the experimental and the numerical cooling of the yarn after cracking. Firstly, this confirms that the specific heat capacity, the thermal conductivities and the mass density are slightly affected by damage and can be chosen as constant. And secondly, this results means that the thermal properties of the composite laminate can be used to model the thermal behaviour of the yarn. Then, using the estimated theoretical heat source, the energy release rate was computed with the following equation derived from Eq. (12):

$G=\frac{1}{\beta} \cdot \frac{1}{e_{c} \cdot l_{c}} \int_{0}^{t} \int_{\Omega} \bar{\omega}_{h s}(x, y, z, t) d \Omega d t$

where $\Omega$ denotes the entire damaged volume.

Approximation of the heat source integrals was calculated using the symbolic integration function of MATLAB 2011b. Energy release rates were hence evaluated with the crack length used for the experimental calculations of $G$. Fig. 10d shows that the crack length represents around 2.4 times the standard deviation $\sigma_{x}$. This estimated crack length is in the same range as the experimental crack length observed on SEM micrographs (Fig. 4). The mean value of G computed for three different heat sources is shown in Fig. 8 (Num. Model.). The results illustrate the underestimation of the energy release rate with the two-dimensional experimental analysis of heat sources. For $\beta=0.9$ and $\beta=0.5$, the energy release rate is respectively underestimated by approximately $18 \%$ and $10 \%$. However, numerically calculated $G$ stays in the same range as interlaminar fracture toughness, as reported in the literature. Differences between experimental and numerical results could be linked to several issues. The first issue is of course the consideration of homogeneous heat source fields through the thickness which lead to underestimation of the thermal dissipated energy in the case of a strong thermal gradient through the thickness. The second issue concerns the spatio-temporal resolution used in the experimental study. Indeed, the pixel size at the maximum resolution of the
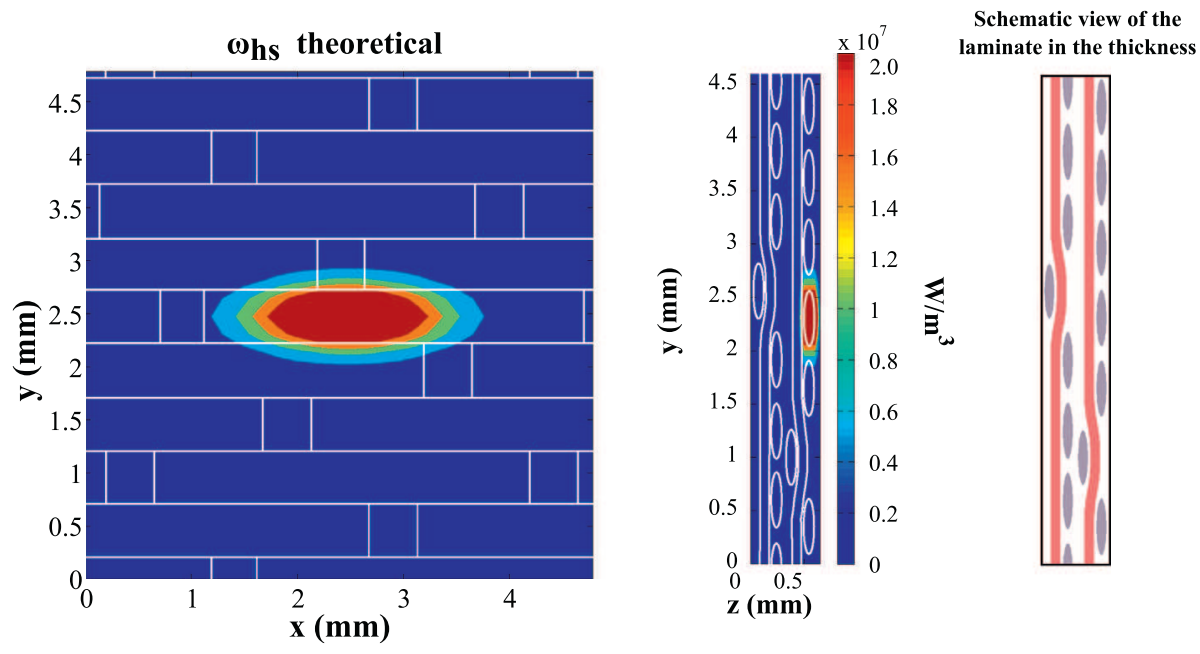

Fig. 9. Numerical spatial representation of the 3D heat source field $\omega_{h s}(x, y, z, t)$ arising from transverse yarn cracking. (For interpretation of the references to color in this figure legend, the reader is referred to the web version of this article.)

Table 2

Values of the theoretical heat source parameters for the three zones shown in Fig. 5b.

\begin{tabular}{lllllll}
\hline $\mathrm{N}^{\circ}$ Zone & $\sigma_{x}(\mathrm{~mm})$ & $\sigma_{y}(\mathrm{~mm})$ & $\sigma_{t}(\mathrm{~s})$ & $\omega_{\max }\left(\mathrm{W} / \mathrm{m}^{-3}\right)$ & $l_{c}(\mathrm{~mm})$ & $\mathrm{e}_{\beta=0.9}\left(\mathrm{~kJ} \mathrm{~m} \mathrm{~m}^{-2}\right)$ \\
\hline 1 & 0.62 & 0.25 & $5.0 \times 10^{-3}$ & $4.4 \times 10^{7}$ & 0.1 \\
2 & 0.62 & 0.25 & $5.0 \times 10^{-3}$ & $4.3 \times 10^{7}$ & 0.56 & 1.32 \\
3 & 0.5 & 0.21 & $5.0 \times 10^{-3}$ & $4.5 \times 10^{7}$ & 0.1 & 0.99 \\
\hline
\end{tabular}




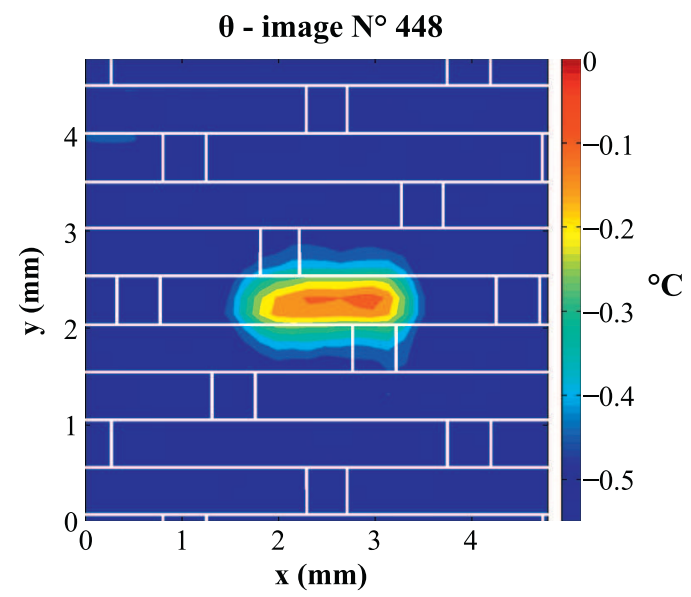

(a)

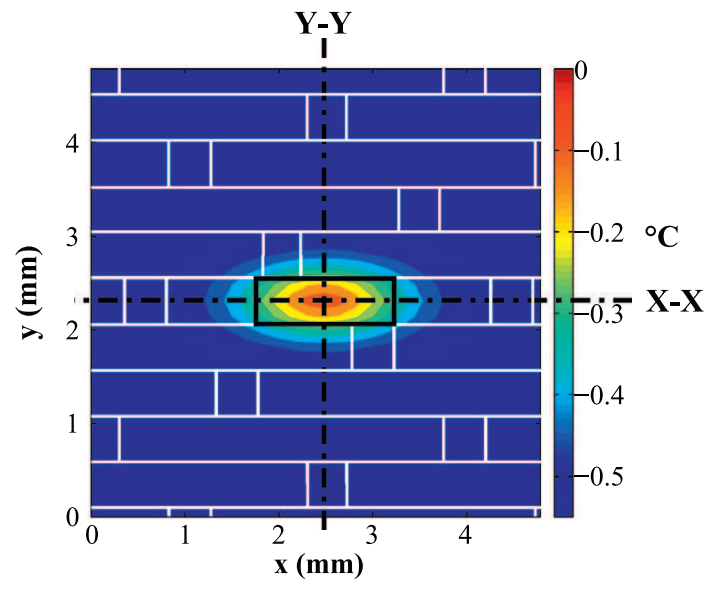

(b)



(d)

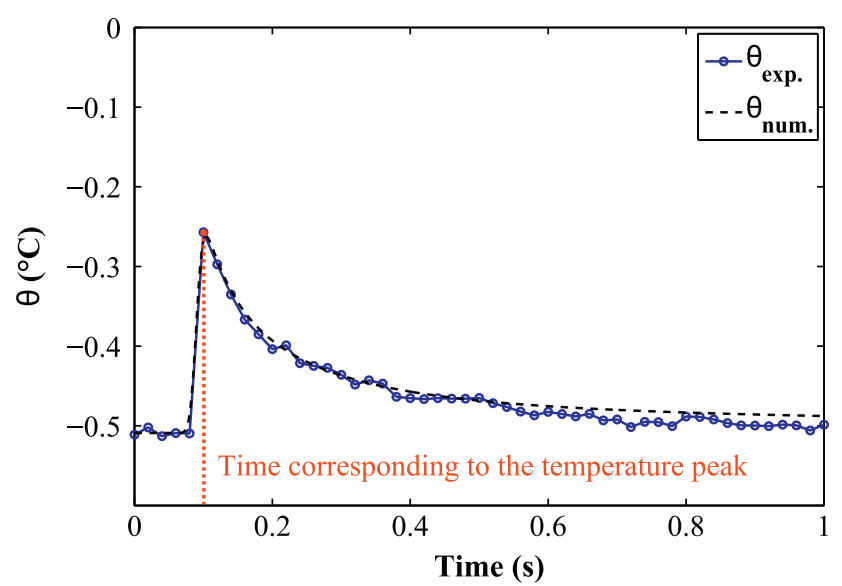

(c)

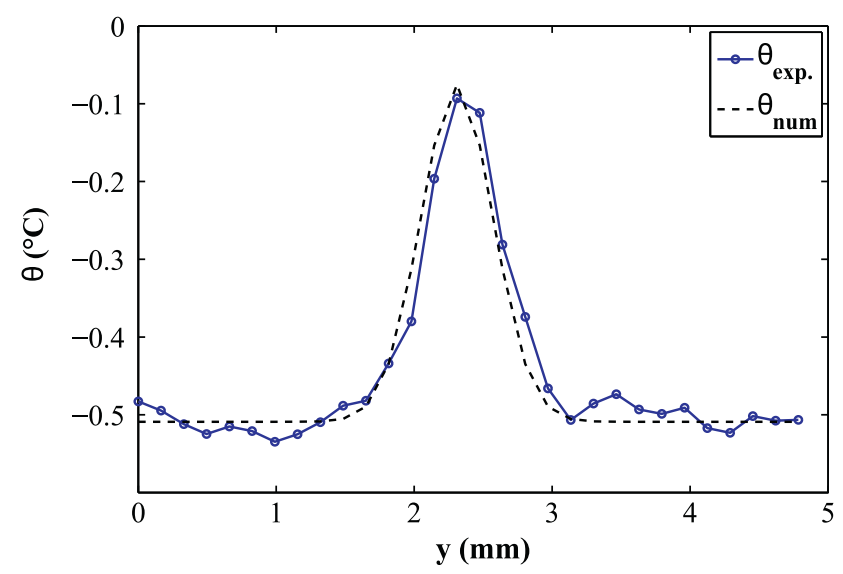

(e)

Fig. 10. (a) Experimental temperature field; (b) Numerical temperature of the weft face, and location of the zone over which numerical and experimental temperature fields are compared; (c) Temporal evolution of the temperature averaged over the rectangular zone; (d) Evolution of the temperature along the $X-X$ axis at the temperature peak; (e) Evolution of the temperature along the $Y-Y$ axis at the temperature peak. (For interpretation of the references to color in this figure legend, the reader is referred to the web version of this article.

infrared camera is about $0.16 \mathrm{~mm}$, which is quite large compared to the yarn size ( 3 pixels in the yarn width). Despite this low spatial resolution Fig. 10e shows that the thermal gradient is still well captured, even if the temperature pic may be underestimated. Thus underestimation of spatial derivative terms may arise from the spatial differentiation of thermal data, even with non-noisy data. The same remark could be made for the evaluation of temporal derivatives. However because the energy release rate estimation requires to integrate these derivatives, the errors made on the energy evaluation induced by the differentiation were attenuated by 
the integration. Nevertheless, the experimental estimation of the energy release rate remains close to numerical calculations, and the depth-wise approximation remains suitable for a first approach to qualitative damage analysis. Although in the case of non-homogeneous heat sources through the thickness, a 3D model of the heat diffusion problem is preferable for quantitative analysis of dissipated energy.

\section{Conclusion}

A comprehensive damage analysis was conducted on $\left[0^{\circ}\right]_{2} 8$ harness satin woven laminates under uniaxial, quasi-static tensile load. Damage scenario was investigated up to failure, combining SEM micrographs and dissipative heat source fields calculated from experimental thermal images. Afterwards, a methodology to estimate the energy release rate by transverse micro-cracking has been proposed and has shown high potential. The analysis of the resulting experimental data led to the following conclusions:

- Transverse weft yarn fracture was confirmed to be the main damage in harness satin woven composites, as reported in the literature. These transverse cracks mainly accumulate between $\varepsilon_{y} \approx 1 \%$ and $\varepsilon_{y} \approx 1.55 \%$, afterwards extension and intersection of transverse cracks represent the main damage modes.

- For woven materials which exhibit low thermal diffusivity through the thickness, such as woven glass/epoxy composites, strong thermal gradients may occur within the thickness during testing. In this context, a 3D model of the heat problem would be preferable to the $2 \mathrm{D}$ heat diffusion model for quantitative analysis of heat source fields, even for thin laminates. The relevance of the 2D approach depends on several parameters: the diffusivity of the material, the thickness of the sample and the distribution of heat sources.

- An experimental procedure has been proposed to estimate the energy release rate in cases where classical compliance methods are inappropriate. The energy release rate obtained for transverse yarn cracking is in the same order of magnitude as typical values of inter-laminar fracture toughness of woven glass/epoxy laminated composites. However inter-laminar and intra-yarn cracks remain tricky to compare, particularly because the crack path and the crack mode are quite different. Moreover, in this study cracks were supposed to propagate as straight lines; which is a disputable assumption considering the SEM micrographs presented. This last point is still a general issue for the experimental evaluation of energy release rates. Hence, here we can only assert that energy release rates associated with transverse yarn cracking are about $1 \mathrm{~kJ} \mathrm{~m}^{-2}$ as typical values of $G$ for polymer materials.

To conclude, we can say that the experimental procedure proposed employing infrared thermography has high potential to monitor damage in time and space for thin woven laminates. With this approach, accurate estimation of energy release rates associated with transverse crack propagation remains tricky, especially without knowing the ratio of mechanical energy converted into heat. Several studies are currently in progress to accurately evaluate the ratio of mechanical energy dissipated as heat. Nevertheless, this experimental method is clearly a relevant alternative to estimate fracture toughness in experiments where classical techniques remain unsuitable.

\section{References}

[1] Gao F, Boniface L, Ogin S, Smith P, Greaves R. Damage accumulation in wovenfabric CFRP laminates under tensile loading: Part 1. Observations of damage accumulation. Compos Sci Technol 1999;59(1):123-36.
[2] John S, Herszberg I, Coman F. Longitudinal and transverse damage taxonomy in woven composite components. Compos B: Eng 2001;32(8):659-68.

[3] Osada T, Nakai A, Hamada H. Initial fracture behavior of satin woven fabric composites. Compos Struct 2003;61(4):333-9.

[4] Daggumati S, Voet E, Van Paepegem W, Degrieck J, Xu J, Lomov S, et al. Local strain in a 5-harness satin weave composite under static tension: Part I experimental analysis. Compos Sci Technol 2011;71(8):1171-9.

[5] Chrysochoos A, Louche H. An infrared image processing to analyse the calorific effects accompanying strain localisation. Int J Eng Sci 2000;38(16):1759-88.

[6] Dumoulin S, Louche H, Hopperstad O, Børvik T. Heat sources, energy storage and dissipation in high-strength steels: experiments and modelling. Eur J Mech - A/Solids 2010;29(3):461-74.

[7] Morabito A, Chrysochoos A, Dattoma V, Galietti U. Analysis of heat sources accompanying the fatigue of 2024 t3 aluminium alloys. Int J Fatigue 2007:29:977-84

[8] Boulanger T. Calorimetric analysis of dissipative and thermoelastic effects associated with the fatigue behavior of steels. Int J Fatigue 2004;26(3):221-9.

[9] Wattrisse B, Muracciole JM, Chrysochoos A. Thermomechanical effects accompanying the localized necking of semi-crystalline polymers. Int J Therm Sci 2002;41(5):422-7.

[10] Chrysochoos A, Chezeaux JC, Caumon H. Analyse thermomécanique des lois de comportement par thermographie infrarouge. Rev Phys Appl 1989;24(2):215-25.

[11] Naderi M, Kahirdeh A, Khonsari M. Dissipated thermal energy and damage evolution of glass/epoxy using infrared thermography and acoustic emission. Compos B: Eng 2012;43(3):1613-20.

[12] Rice J. A path independent integral and the approximate analysis of strain concentration by notches and cracks. J Appl Mech 1968;35:379-86.

[13] Moran B, Shih C. Crack tip and associated domain integrals from momentum and energy balance. Eng Fract Mech 1987;27(6):615-42.

[14] Freund L, Hutchinson J. High strain-rate crack growth in rate-dependent plastic solids. J Mech Phys Solids 1985;33(2):169-91.

[15] Soumahoro Z. Etude du couplage thermomécanique dans la propagation dynamique de fissure. Ph.D. thesis. Ecole Polytechnique; 2005.

[16] Taylor GI, Quinney H. The latent energy remaining in a metal after cold working. Proc Roy Soc A: Math, Phys Eng Sci 1934;143(849):307-26.

[17] Kapoor R, Nemat-Nasser S. Determination of temperature rise during high strain rate deformation. Mech Mater 1998;27(1):1-12.

[18] Li Z, Lambros J. Strain rate effects on the thermomechanical behavior of polymers. Int J Solids Struct 2001;38(20):3549-62.

[19] Rittel D. On the conversion of plastic work to heat during high strain rate deformation of glassy polymers. Mech Mater 1999;31(2):131-9.

[20] Benevolenski OI, Karger-Kocsis J, Czigány T, Romhány G. Mode I fracture resistance of glass fiber mat-reinforced polypropylene composites at various degree of consolidation. Compos A: Appl Sci Manuf 2003;34(3):267-73.

[21] Germain P. Cours de mécanique des milieux continus. Theorie générale, vol. Tome I. Paris: Masson et Cie; 1973.

[22] Lemaitre J, Chaboche JL, Benallal A, Desmorat R. Mécanique des matériaux solides. Dunod; 1985

[23] Fiedler B, Hojo M, Ochiai S, Schulte K, Ando M. Failure behavior of an epoxy matrix under different kinds of static loading. Compos Sci Technol 2001;61(11):1615-24.

[24] Okabe T, Nishikawa M. Toyoshima H. A periodic unit-cell simulation of fiber arrangement dependence on the transverse tensile failure in unidirectional carbon fiber reinforced composites. Int J Solids Struct 2011;48(20):2948-59.

[25] Kołodziej JA, Mierzwiczak M, Ciałkowski M. Application of the method of fundamental solutions and radial basis functions for inverse heat source problem in case of steady-state. Int Commun Heat Mass Transfer 2010;37(2):121-4.

[26] Zhang D, Hayhurst D. Influence of applied in-plane strain on transverse thermal conductivity of $0^{\circ} 190^{\circ}$ and plain weave ceramic matrix composites. Int J Solids Struct 2011;48(5):828-42.

[27] Döll W. An experimental study of the heat generated in the plastic region of a running crack in different polymeric materials. Eng Fract Mech 1973;5(2):259-68.

[28] Weichert R, Schönert K. On the temperature rise at the tip of a fast running crack†. J Mech Phys Solids 1974;22(2):127-33.

[29] Weichert R, Schönert K. Heat generation at the tip of a moving crack. J Mech Phys Solids 1978;26(3):151-61.

[30] Griffith AA. The phenomena of rupture and flow in solids. Philos Trans Roy Soc A: Math, Phys Eng Sci 1921;221(582-593):163-98.

[31] Bizeul M, Bouvet C, Barrau J, Cuenca R. Influence of woven ply degradation on fatigue crack growth in thin notched composites under tensile loading. Int J Fatigue 2010;32(1):60-5.

[32] Hobbiebrunken T, Hojo M, Adachi T, De Jong C, Fiedler B. Evaluation of interfacial strength in $\mathrm{CF} /$ epoxies using FEM and in-situ experiments. Compos A: Appl Sci Manuf 2006;37(12):2248-56.

[33] Spiteri P. Méthode des différences finies pour les EDP d'évolution. af501. Techniques de l'ingénieur; 2002.

[34] Alif N, Carlsson LA, Boogh L. The effect of weave pattern and crack propagation direction on mode i delamination resistance of woven glass and carbon composites. Compos B: Eng 1998;29(5):603-11.

[35] Pereira A, de Morais A, de Moura M, Magalhães A. Mode i interlaminar fracture of woven glass/epoxy multidirectional laminates. Compos A: Appl Sci Manuf 2005;36(8):1119-27. 
[36] Gill AF, Robinson P, Pinho S. Effect of variation in fibre volume fraction on modes I and II delamination behaviour of 5HS woven composites manufactured by RTM. Compos Sci Technol 2009;69(14):2368-75.

[37] Bigaud D, Goyhénèche JM, Hamelin P. A global-local non-linear modelling of effective thermal conductivity tensor of textile-reinforced composites. Compos A: Appl Sci Manuf 2001;32(10):1443-53.
[38] Emery T, Dulieu-Barton J, Earl J, Cunningham P. A generalised approach to the calibration of orthotropic materials for thermoelastic stress analysis. Compos Sci Technol 2008;68(3-4):743-52 